\title{
Ultrafine particles: Exposure and source apportionment in 56 Danish homes
}

Gabriel Bekö $^{1 *}$, Charles J. Weschler ${ }^{1,2}$, Aneta Wierzbicka ${ }^{3}$, Dorina Gabriela Karottki ${ }^{4}$, Jørn Toftum ${ }^{1}$, Steffen Loft ${ }^{4}$, Geo Clausen ${ }^{1}$

${ }^{1}$ International Centre for Indoor Environment and Energy, Dept. of Civil Engineering, Technical University of Denmark, Nils Koppels Allé 402, 2800-Lyngby

${ }^{2}$ Environmental and Occupational Health Sciences Institute, University of Medicine and Dentistry of New Jersey and Rutgers University, 170 Frelinghuysen Road, Piscataway, NJ 08854, USA

${ }^{3}$ Division of Ergonomics and Aerosol Technology, Lund University, P.O. Box 118, SE-221 00 Lund, Sweden

${ }^{4}$ Department of Public Health, University of Copenhagen, Øster Farimagsgade 5, 1014 Copenhagen, Denmark

\section{Supporting Information}

Number of pages: 16 (S1-S16)

Number of Figures: 5 (S1-S5)

Number of Tables: 5 (S1-S5) 


\section{Instrument accuracy}

The instrument electrically charges the particles in the sampled airflow and subsequently measures the particle-bound charge concentration. It uses a unipolar diffusion charger to electrically charge the aerosol particles. The particle size distribution is manipulated in a low-efficiency electrostatic precipitator (ESP). Intermittently, a low voltage to remove only ions and a higher voltage to manipulate the particle size distribution are applied to the ESP. The current from the particles exiting the ESP is continuously measured with a Faraday cup electrometer. Total particle number concentration and mean particle size are derived from the current values during the two periods with different ESP voltages. The instrument uses a fan to establish the aerosol flow rate of $0.3-0.4 \mathrm{~L} / \mathrm{min}$, which reduces noise and battery consumption but doesn't allow for the use of a pre-separator for large particles. ${ }^{1,2}$

The instrument does not offer size resolution, only total particle count in the specified size range (10$300 \mathrm{~nm}$ ). The instrument was operated in Advanced mode, which also provides the average particle diameter. The instrument's resolution, as specified by the manufacturer, is $\pm 1,500 \mathrm{~cm}^{-3}$ for particle concentration and $\pm 10 \mathrm{~nm}$ for particle diameter. An independent study comparing the performance of portable nanoparticle monitors reported an accuracy of the measured number concentrations and particle diameters to be $\pm 30 \%$. ${ }^{1}$ According to the manufacturer, the average particle diameter may not be accurate at particle concentrations below $10,000 \mathrm{~cm}^{-3}$. The instrument's number concentration range is $0-10^{6} \mathrm{~cm}^{-3}$, and the average particle diameter range is $20-120 \mathrm{~nm}$. Values outside these limits may be subject to increased uncertainties. The instrument may overestimate the concentration of particles, when their modal diameter is beyond the instruments specifications $(20-120 \mathrm{~nm})$. A steep gradient in both concentration and particle size can result in a significant increase of the currents measured with the Faraday cup electrometer. In such a case, the data deconvolution algorithm may misinterpret the increase as a very high concentration. ${ }^{1}$

After all measurements were completed, the instruments were collocated and their performance was compared in an aerosol chamber against a Scanning Mobility Particle Sizer (SMPS 3934, TSI Inc., USA). The particle size range measured by the SMPS was set to 10-360 $\mathrm{nm}$ in order to reduce the scanning time, while covering the range measured by the NanoTracer. Particles from three typical indoor sources (candle, incense, cigarette smoke) were generated and used for comparisons. There was no particular pattern in the results obtained for the three instruments or the various source types. Therefore, raw data without adjustment were used for analyses. As incense burning and cigarette smoke did not occur in the studied homes, we focus on results from candle burning. Two budget candles made from a stearin and paraffin mixture, and typically used in Scandinavian homes, were used in the experiment.

Particle number size distribution during peak concentrations (3-minute average) and 1-hour average distribution based on the data from the SMPS is presented in Figure S1 (note the log-scale on the yaxis). The figure indicates potentially large contribution of particles smaller than $\sim 10 \mathrm{~nm}$ to peak concentrations; hence the total PN concentrations may be underestimated. Bi-modal size distribution was observed with modes at $\sim 10 \mathrm{~nm}$ and at $\sim 280 \mathrm{~nm}$. Our results obtained for one type of candle may not be representative of all candle events in the 56 homes. The contributions of the nucleation and accumulation modes to the total PN concentration may depend on the type of candle and burning mode. However, the bi-modal size distribution agrees well with what has been reported in other studies. Stabile et al. ${ }^{3}$ reported a distribution for a paraffin wax candle with dominating mode at $\sim 30-40 \mathrm{~nm}$ and a trace of mode at $\sim 150 \mathrm{~nm}$. Pagels et al. ${ }^{4}$ observed bi-modal size distribution with dominating nucleation mode (20-30 nm) during steady burn and accumulation mode $(\sim 300 \mathrm{~nm})$ during sooting of a pure stearin candle and a candle made of a mixture of stearin and paraffin. In Figure 6 of Wallace ${ }^{5}$ bimodal size distribution is reported for a citronella candle with modes at $\sim 50 \mathrm{~nm}$ and $\sim 150 \mathrm{~nm}$. Sun et 
al. ${ }^{6}$ observed the highest concentrations for particles between $25-50 \mathrm{~nm}$ in diameter during various burning modes of a paraffin candle in a test chamber.

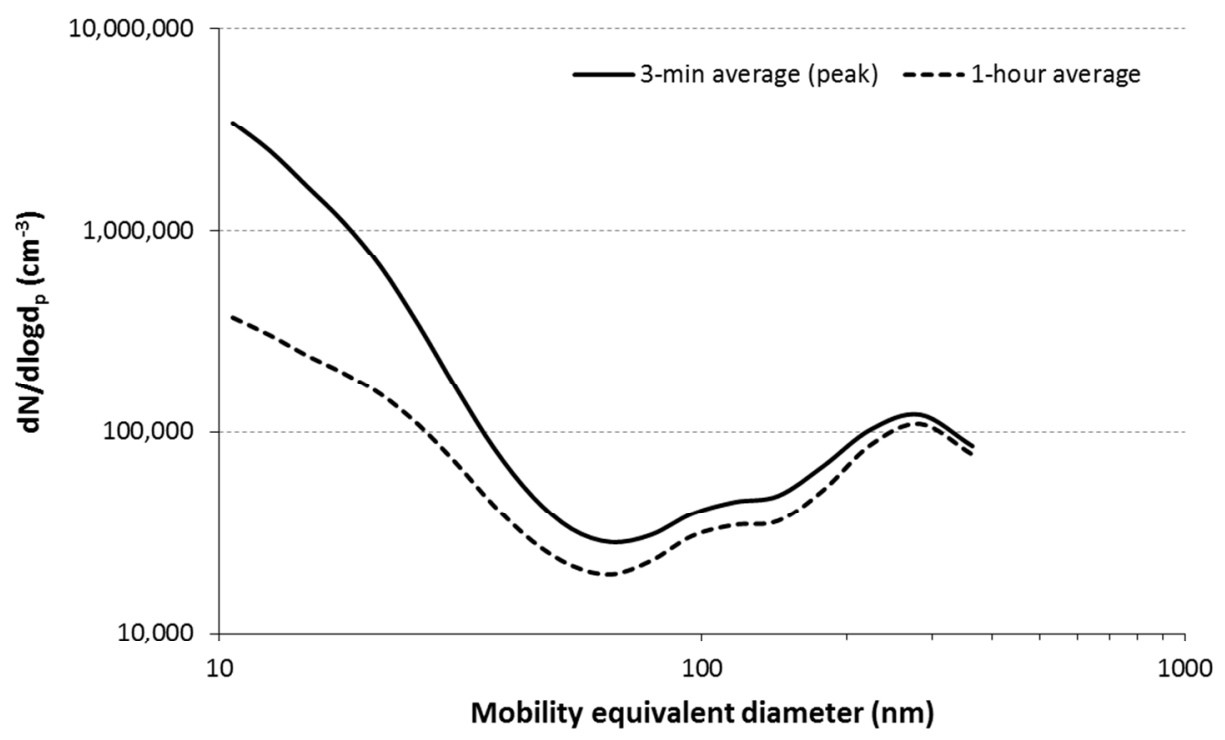

Figure S1. Particle number distribution by particle size during candle burning. Three-minute average values during peak concentrations and 1-hour average values are shown. Data were obtained by SMPS in the size range $10-360 \mathrm{~nm}$.

Particle number concentrations and average diameters measured with SMPS and three NanoTracers (average of the three) are shown in Figure S2. Concentrations from the NanoTracers were lower during elevated concentrations. Thus, during this particular candle event, the NanoTracers underestimated the peak PN concentrations. The NanoTracer-to-SMPS ratio for the 9-minute average peak concentration ranged between 0.4 and 0.8 for the three NanoTracers. Better agreement of the two types of instruments was observed when the average concentrations over the entire event were compared. The NanoTracer-to-SMPS ratio for the 1-hour average concentrations was $0.61,1.02$ and 1.08 for the three NanoTracers. It is apparent from Figure S2 that the NanoTracers started to slightly overestimate the PN concentrations (by a factor of two at most) after the indicated average particle diameters reached $\sim 140$ $\mathrm{nm}$ (specifically at $\sim 125,140$ and $150 \mathrm{~nm}$ for the three NanoTracers, respectively). This occurred at PN concentrations much lower than the peak PN levels.

Our candle experiment indicates that extreme PN concentrations during some of the candle events that occurred in the 56 homes may have been underestimated. Indeed, the highest PN concentrations in the homes were observed when the average particle diameters were $20-35 \mathrm{~nm}$. This size range agreed reasonably well with those observed with the SMPS. Asbach et al. ${ }^{1}$ reported an overestimation of particle number concentrations by the NanoTracer by a factor of $\sim 7$ for di(2-ethylhexyl) sebacate particles with a modal diameter of $180 \mathrm{~nm}$, which is above the instrument's reliable upper limit of 120 $\mathrm{nm}$. Some overestimation of concentrations due to the presence of larger particles (e.g. during burning of certain candle types) may have occurred, but presumably at much lower concentrations. Hence, the impact of such events on our current results may be less pronounced. Analyzing all data points from the 56 homes, the mean particle diameter was $76 \mathrm{~nm}$, while only $5 \%$ of values were above $120 \mathrm{~nm}$ and only $0.2 \%$ were below $20 \mathrm{~nm}$. Additionally, underestimated peak levels and overestimated levels towards the end of the elevated concentrations may result in an even smaller error in the integrated 
exposure (area below the curve) corresponding to the event. Therefore we believe that our results and their interpretations are not in serious error.

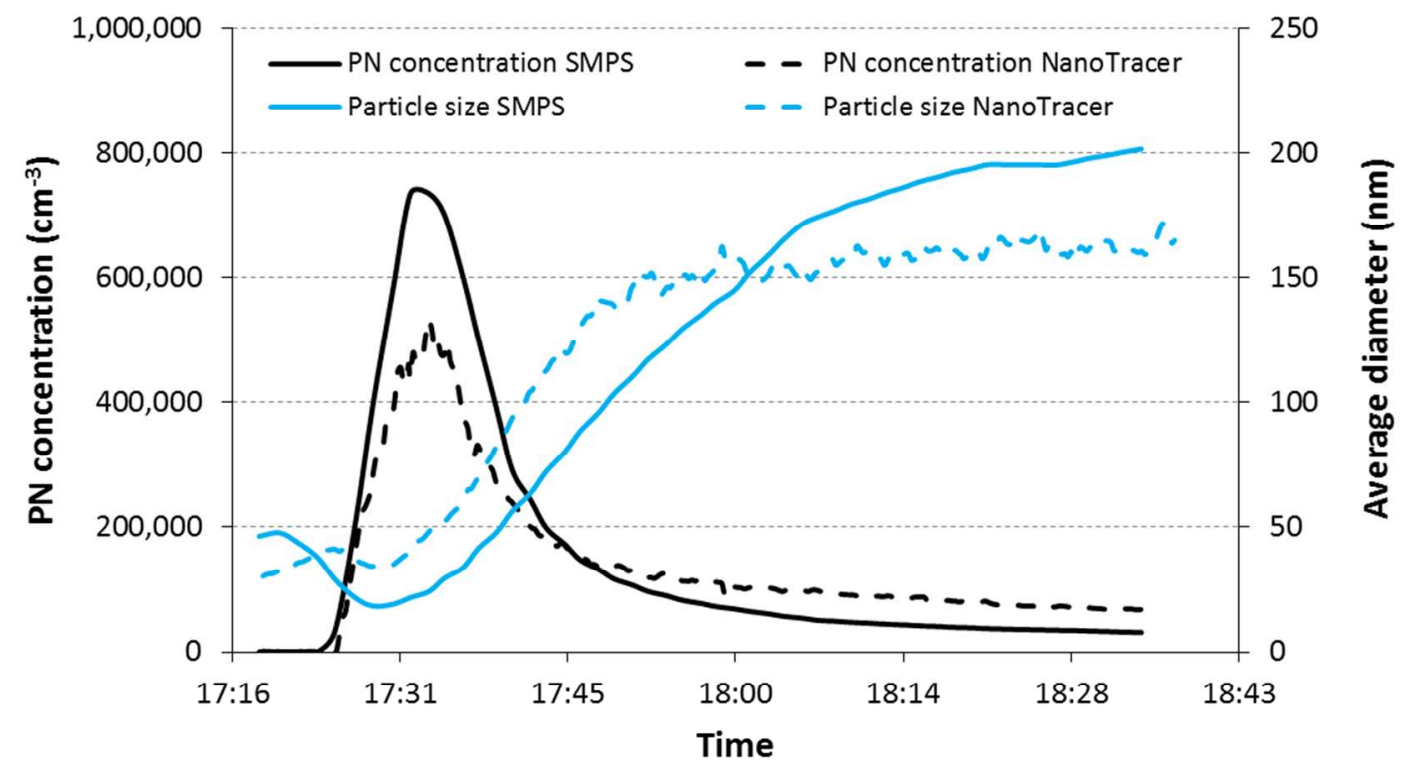

Figure S2. Particle number concentrations and average particle diameters measured with SMPS (10$360 \mathrm{~nm})$ and three NanoTracers $(10-300 \mathrm{~nm})$ during burning a candle in a chamber. NanoTracer data represent averages of the three instruments.

The average particle diameters measured by the NanoTracer within its reliable range (20-120 nm) followed the trend of those obtained with the SMPS. However, the NanoTracer tended to overestimate the true particle size. The Nanotracer-to-SMPS average particle size ratio during the 9 minutes of peak concentrations ranged between 1.7 and 2.3 for the three NanoTracers. This ratio was between 0.9 and 1.2 for the 1-hour average values, indicating better agreement with SMPS when averaging over a larger size range.

In nine homes, especially while burning candles, the highest observed concentration exceeded $10^{6} \mathrm{~cm}^{-3}$, which is outside the instrument's number concentration range. However, these readings from the instruments can still be reliable as long as the sensor signal (current) does not exceed the maximum of $10 \mathrm{pA}$ (personal communication with the manufacturer). The measured current depends on the particle concentration and the average particle size; the maximum measurable concentration decreases with increasing particle size. The maximum measurable concentration at a given average particle size can be calculated using the maximum sensor signal. ${ }^{7}$ For an average particle diameter of $20 \mathrm{~nm}$, the highest reliable particle concentration would be $12.6 \times 10^{6} \mathrm{~cm}^{-3}$, while that for $35 \mathrm{~nm}$ particles would be 7.2 $\mathrm{x} 10^{6} \mathrm{~cm}^{-3}$. In our study the average particle diameter during candle burning ranged between 20 and 35 $\mathrm{nm}$. The highest concentration reached during all such events $\left(2.2 \times 10^{6} \mathrm{~cm}^{-3}\right)$ was lower than the corresponding highest reliable concentration.

Treatment of peaks attributable to more than one source and of two subsequent events Certain peaks could be attributed to more than one source. We were unable to estimate the respective contribution from several co-occurring source events when they resulted in a single peak. We then compared the peak to similar single-source peaks. When we judged that the source strength of one source could clearly overwhelm that of the other, we assigned the peak to the dominant event. For example, cooking and candle burning were in several cases co-occurring events resulting in a single 
peak. However, the particle concentration peak attributable to candle burning alone had a distinctive pattern of steadily fluctuating concentrations made up of somewhat scattered data points; all at concentrations much higher than usually observed for cooking events (Figure 1 in the manuscript and Figure S3). In such cases the peak was attributed to a candle event. When the window was reported open during other source events, especially cooking, it presumably acted as a sink for the much higher PN concentrations indoors than outdoors. Its effect on the PN concentrations in such situations has been disregarded in the present study.

When two events followed each other so closely that the PN concentration after the first did not reach the background level before the second event started, we calculated the respective integrated exposure from each separate event to the best of our ability (Figure S3). The concentration decay of the first event was linearly extended towards the background concentration reached after the second event. Thus, we attributed a reasonable fraction of the exposure (area) under the second peak to the first source event. The background PN concentration for both events was calculated as the average of the PN concentration before the beginning of the first event and the background PN concentration reached at the end of the second one. The exposure duration of the first event was difficult to determine precisely. It was calculated as the sum of its source duration and the duration of concentration decay of the second event. This approach assumes that it would take the same time after both events for the PN concentration to return to the background level, regardless of the peak's magnitude. Given the logarithmic nature of the decay, the error resulting from this assumption is believed to be relatively small. Our approach to separate the effects of two subsequently occurring events is overly simplified and does not consider any interaction between particles from the different sources (e.g. coagulation). However, we believe that our results reasonably estimate the relative contribution of the various types of events to total particle exposure.

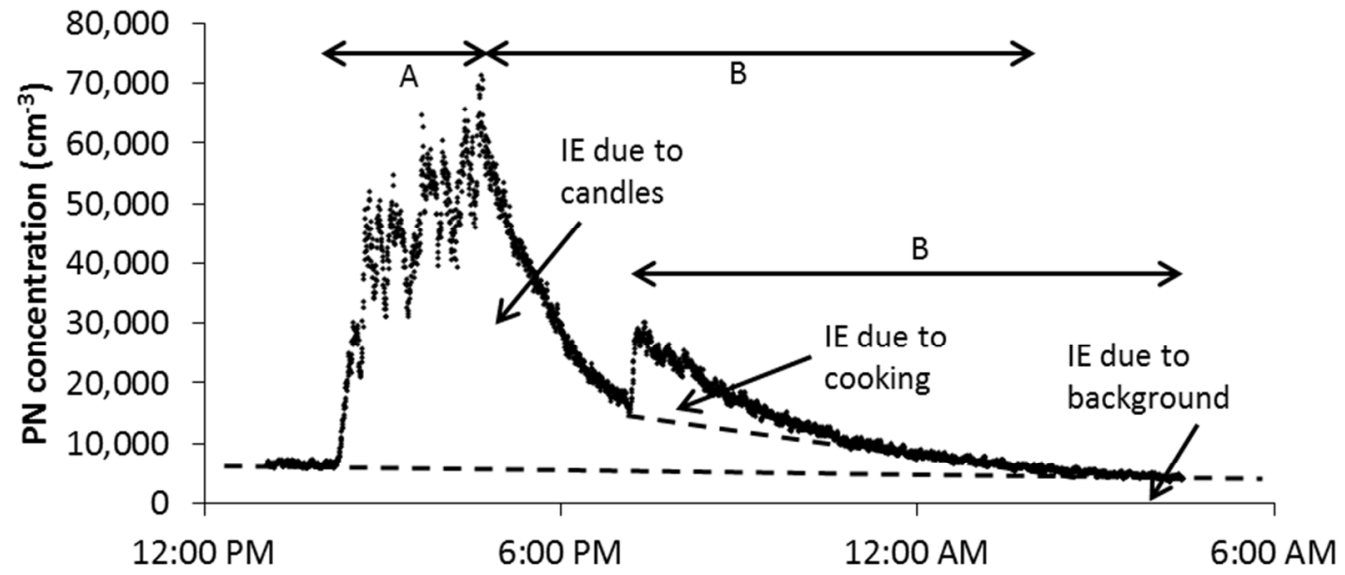

Figure S3. Example of data treatment for two subsequent events. IE-integrated exposure, A-source duration, B-period of concentration decay, $(\mathrm{A}+\mathrm{B})$-exposure duration.

\section{Discussion on the potential sources of unknown events}

We obtained 30-minute average outdoor PN concentrations in the corresponding size range (10-300 $\mathrm{nm}$ ) from two monitoring stations in Copenhagen. One monitoring station was located at an urban background site on the roof of a public building, and data were obtained for most days in the periods between 11 November and 15 December 2011 and between 1 and 15 February 2012. The other station was at street level on one of Copenhagen's busiest streets. These data were obtained for the period between 16 November 2011 and 15 February 2012. Higher concentrations were measured at street 
level compared to the urban background station. The time-matched data from the two monitoring stations were averaged, in order to obtain reasonable average outdoor PN levels for homes both on busy streets and on less trafficked streets throughout the city. Figure S4a shows an example of timeseries of 30-minute average outdoor concentrations between 16 November and 16 December 2011. The figure indicates that the outdoor PN concentration pattern is similar for most days of the month and the average concentration rarely exceeds $20000 \mathrm{~cm}^{-3}$, which is far below the concentrations achieved by the peaks during indoor source events. Figure S4b depicts time-series of outdoor PN concentrations during a representative 24-hour period. The data from all available days were averaged into a single 24hour time series plot of 30-minute outdoor UFP concentrations (Figure S4c). Given the relatively low levels of UFP in the outdoor air in Copenhagen and the lack of sharp and extensive peaks in outdoor PN levels, we believe that the observed changes in outdoor PN levels would not result in indoor concentration patterns identifiable as peaks by the criteria described in this paper. Instead, changes of longer duration would be reflected in increased background indoor levels. This is further supported by the fact that daytime window opening resulted in minor changes and contributed almost negligibly to the total residential exposure. Moreover, the time of occurrence, the extent and pattern of the unknown peaks suggest that they are chiefly caused by indoor sources.

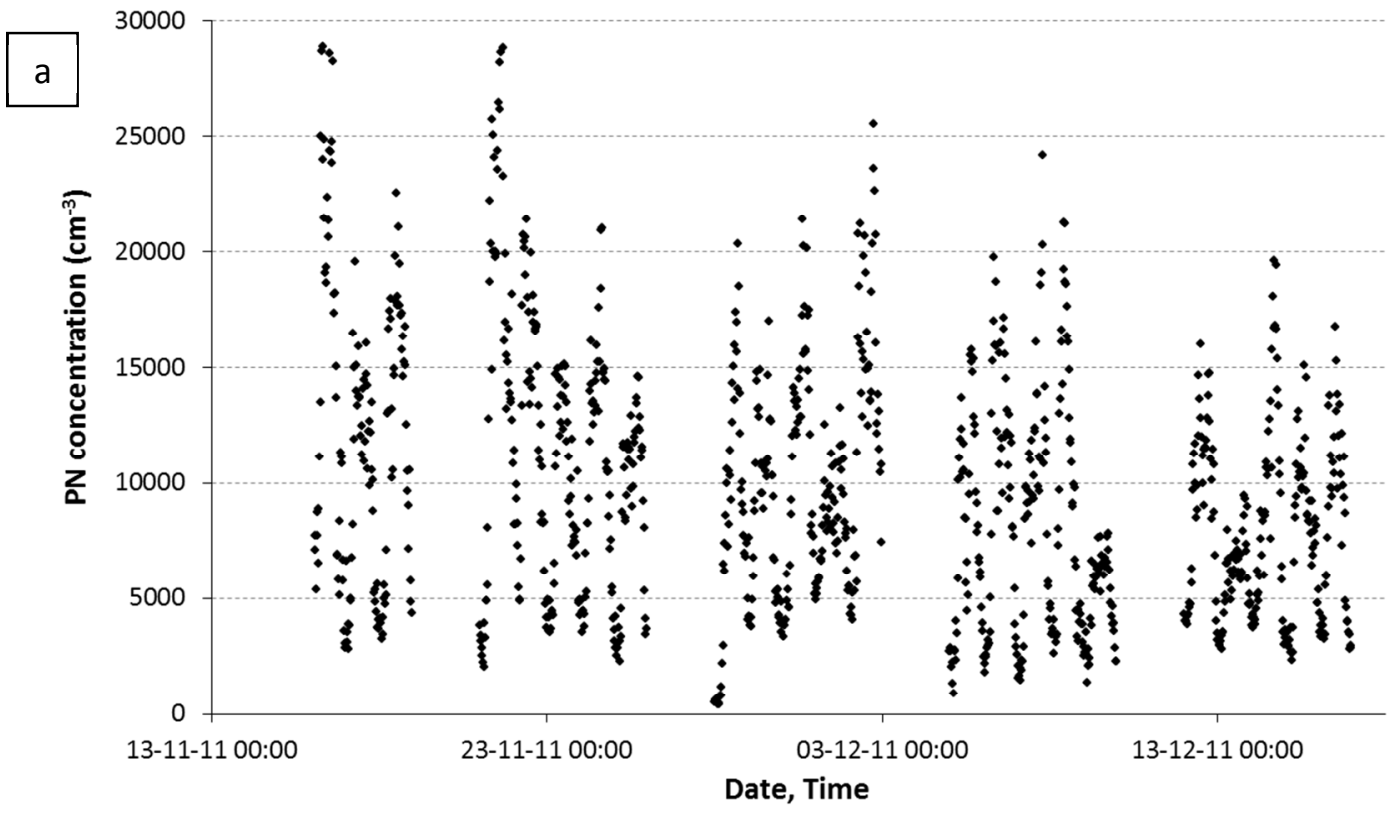



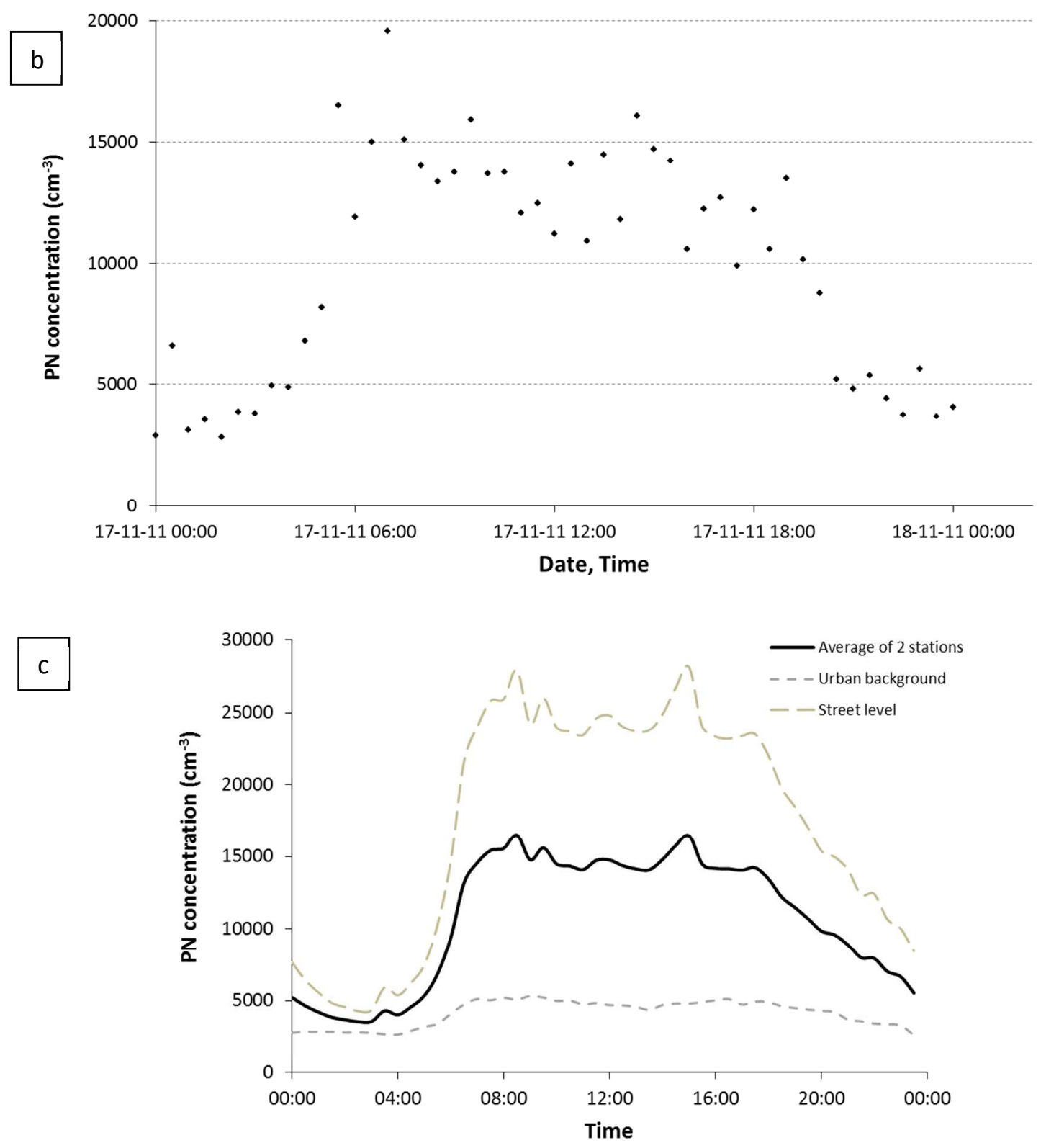

Figure S4. a) Example of time-series of 30-minute average outdoor concentrations (between 16 November and 16 December 2011); b) time-series of outdoor PN concentrations during a representative 24-hour period; c) diurnal pattern of 30-minute outdoor UFP concentrations averaged over the period from mid-November 2011 to mid-February 2012.

Cross-apartment flows may have contributed to some of the unknown peaks. However, our unknown sources occurred with roughly the same frequency in single family houses and apartments. All unknown peaks occurred during occupied periods. Moreover, in several homes the activity log books were distributed to two family members and the indicated activities did not always match between the two occupants. This indicates that the occupants might have filled in the log book at the end of the measurement period and may have recalled the activities imperfectly. Additionally, while crossapartment transmission of particles is not limited to tobacco smoke, it is important to note that none of the occupants reported the smell of smoking from neighbors, which was part of the questionnaire. 
Therefore we believe most of the unknown events were due to indoor sources within the measured homes.

After comparing the times of occurrence and the PN patterns to those of identified events, we speculate that the majority of the unknown events were related to cooking. A fraction of the unknown events took place in the morning of the third day, before the instruments were removed. They may be related to unrecorded breakfast activities, as the log-books did not contain a separate questionnaire for this day. Relatively small, but identifiable peaks were observed at the very beginning of several of the measurements. During this "beginning time" the occupants engaged in routine activities that were often not recorded. Moreover, the researchers inspected the home and collected samples of settled dust using a vacuum cleaner and may have contributed to unknown source events during this initial period. We consider these data from the beginning and end of the measurement periods sufficiently valuable to be included in the analyses as "unknown source events".

\section{Comparison of average background concentrations estimated by different approaches}

The average indoor background PN concentration in each home was calculated as the time-weighted average of the concentration during the periods when the occupants were asleep and when the home was unoccupied. Alternatively, the average indoor background exposure concentration can be determined by dividing the difference between the total integrated exposure during the occupied periods and the net exposure from all peaks calculated from the event-specific background concentrations, by the duration of occupancy. The event-specific background concentration was determined for each event as the average of the stable PN concentration at the beginning of the event and at the end of the elevated PN concentrations. Table S1 compares all these background concentrations. The event-specific background concentrations are based on a subset of 110 events that occurred in 30 homes.

Table S1. Comparison of average background PN concentrations in the 56 homes determined by various approaches.

\begin{tabular}{lccc}
\hline Approach & Mean (SD) & Median & Geometric mean \\
\hline Unoccupied periods & $4563(2029)$ & 4276 & 4137 \\
Periods of sleep & $3293(1456)$ & 2931 & 2986 \\
Unoccupied p. and p. of sleep* & $3780(1761)$ & 3386 & 3413 \\
From difference between total exp. and net exp. & $4497(1944)$ & 4380 & 4076 \\
from peaks & & & 4766 \\
Event-specific & $5190(2099)$ & 5075 & 4 \\
\hline
\end{tabular}

* time-weighted average of the concentrations during the two periods

The background PN concentrations in the 56 homes determined by the various approaches were similar, especially relative to concentrations during source events, which were often orders of magnitude higher than any of these background levels. We believe that using the time-weighted average of the background concentration during the periods when the occupants were asleep and when the home was unoccupied is more reasonable than using the background concentrations determined from the difference between the total integrated exposure and the net exposure from the peaks. This way, our background levels more precisely represent both night periods and periods of vacancy. Moreover, the net exposure from the events relies on the determination of the event-specific background concentration, which was not always straightforward; it proved to be challenging especially when several events took place sequentially (see above). However, the event-specific background concentrations were only slightly higher compared to the daily background levels estimated by the other approaches. (The concentrations at the beginning of the event and at the end of 
the elevated PN concentrations, the average of which was used to obtain the event-specific background concentration, were always close to each other, as the end of a peak was identified when the concentration had declined to a level similar to that before the peak's beginning).

The integrated exposure estimated from all analyzed peaks explained on average $92 \%$ of the fraction of the total daily exposure above the background daily exposure (calculated from the time-weighted average indoor background concentration during nights and unoccupied periods). Moreover, the average unexplained difference between the total residential exposure and the sum of exposures attributed to the indoor background PN concentrations and to the analyzed events was only $4.5 \%$ of the total exposure. These data further indicate that the overall indoor background concentrations and the event-specific background concentrations were reasonably well estimated.

\section{Comparison of average background concentrations with the estimated indoor proportion of outdoor particles based on concentrations from outdoor monitoring stations}

We obtained 30-minute average outdoor PN concentrations in the corresponding size range (10-300 $\mathrm{nm}$ ) from two monitoring stations in Copenhagen (see above). The times of the outdoor data from both monitoring stations were matched with the times of the indoor data from the 56 homes. An average outdoor PN concentration from each monitoring station was calculated for each corresponding indoor measurement period. These average outdoor levels from the two monitoring stations were further averaged to obtain one average outdoor PN concentration for each home during the time of our indoor measurements. Valid average outdoor PN concentrations (data from both outdoor monitoring stations available for the days of our indoor measurements) were obtained for 29 homes.

For the 29 homes with an average outdoor PN concentration, we estimated the indoor proportion of outdoor particles using the measured air exchange rates and a penetration factor $(0.55)$ and deposition rate constant $\left(0.65 \mathrm{~h}^{-1}\right)$ estimated from the literature for particle diameter of $90 \mathrm{~nm}$ (average indoor particle size during nights; see Table 1 in the manuscript). ${ }^{8,9}$ We then compared these estimated average indoor concentrations of particles originating outdoors (GM: $3432 \mathrm{~cm}^{-3}$; mean: $3664 \mathrm{~cm}^{-3}$; range: $1972-7827 \mathrm{~cm}^{-3}$ ) with our average indoor background concentrations obtained from the measurements during periods when the occupants were asleep and when the homes were unoccupied (GM: $3413 \mathrm{~cm}^{-3}$; mean: $3780 \mathrm{~cm}^{-3}$; range: $1276-10513 \mathrm{~cm}^{-3}$ ). The I/O concentration ratios based on the average outdoors levels and the average indoor background levels (GM: 0.37; mean: 0.42; range: 0.12 1.08) were very similar to the ratios calculated using the estimated average indoor proportion of outdoor particles (GM: 0.34; mean: 0.35; range: $0.21-0.47$ ). These ratios are in line with infiltration factors (I/O ratios) previously reported for naturally ventilated buildings with mostly closed windows. ${ }^{8-}$

${ }^{16} \mathrm{We}$ calculated the ratio of our average background PN concentrations and the estimated average indoor proportion of outdoor particles for the 29 homes. The geometric mean of this ratio was 1.1. Although the above described estimates may be imperfect, they indicate that our estimates of the average background PN levels reasonably represent the indoor PN levels attributable to the penetration of outdoor particles.

\section{Discussion on the ratios of the average indoor PN concentration to the average indoor background concentration}

The average indoor background PN concentrations reflect the concentrations during the periods when no episodic source events were impacting PN levels - when the homes were unoccupied or the occupants were asleep. It is reasonable to assume that infiltration of outdoor particles was responsible for most of the indoor background PN levels (see above). We use these concentrations as a proxy for the outdoor concentrations that were not measured. The geometric mean ratio of the average indoor PN concentration to the average indoor background concentration was 1.7 during periods when the homes 
were unoccupied, 1.5 when the occupants were presumably asleep, 6.5 when the occupants were awake and 5.1 when at least one occupant was present (occupied periods, both awake and asleep). The differences between these ratios were statistically significant for all pairs $(p<0.05$; nonparametric Wilcoxon signed rank test for matched pairs). These ratios clearly support earlier observations that high indoor PN levels and high indoor-to-outdoor $(\mathrm{I} / \mathrm{O})$ ratios coincide with periods when occupant related indoor sources are present. However, the absolute values of these ratios have to be interpreted with caution, as they are not the same as the I/O ratio. The average indoor background concentrations were determined from the PN concentrations measured during the periods when the occupants were asleep and when the homes were unoccupied (see above). We commonly encountered that a source event occurred immediately prior to the occupants leaving the home (e.g. toasting during breakfast) or prior to midnight - the assumed bedtime (e.g. late candle burning). The increased PN levels due to such events often lasted after the beginning of the unoccupied or sleep periods. Thus, when calculating the background levels we have excluded data from fractions of the unoccupied and sleep periods during which the PN levels were clearly elevated following an identified peak/event. These data were not excluded from the average indoor PN concentrations. For this reason the geometric mean ratios of the average indoor PN concentration to the average indoor background concentration during periods when the homes were unoccupied or when the occupants were presumably asleep were larger than one. If outdoor particle levels were available, I/O ratios would have been similarly high, unless the periods with source events were excluded.

\section{Stratification of daily integrated exposure on selected building characteristics}

Differences in integrated exposures stratified by various building characteristics were tested with parametric (Student's two-sample t-test with equal or unequal variances, as applicable) and nonparametric tests (two-sample Wilcoxon Mann-Whitney rank-sum test), as the daily integrated exposures were not fully normally distributed (Tables S2-S4). Whenever possible, variable categories with too few observations were collapsed into the closest relevant categories. This was done to make the statistical comparisons more robust.

Background exposure, which is mainly due to ultrafine particles entering the home from outdoors, was significantly lower in homes located farther from heavily trafficked roads and lower in family houses than apartments. These results may reflect more rural locations of houses compared to apartments. The home's vicinity to a major roadway did not lead to significant differences in the integrated daily exposure from source events, or in the total residential daily exposure. This is in line with expectations, since indoor sources contribute the most to the overall residential PN exposure.

Significantly lower daily exposure from source events and lower total residential daily exposure were observed in houses compared to apartments. This may reflect larger volumes of houses and greater dilution of indoor PN concentrations compared to apartments. This hypothesis is further supported by the observation that the exposures from indoor sources and the total exposures, but not the exposures from background PN levels, were significantly lower in dwellings with larger floor area.

The differences in exposures were not significant when the data was stratified by air exchange rate, having mechanical exhaust ventilation in the bathroom (other than fan controlled by humidity or the light switch), number of occupants or cooking on a gas stove. 
Table S2. Background daily integrated PN exposure calculated from the average indoor background PN concentration $\left(x 10^{3} \mathrm{~cm}^{-3} \mathrm{~h} / \mathrm{d}\right)$ stratified on selected building characteristics $(\mathrm{n}=56)$.

\begin{tabular}{|c|c|c|c|c|c|c|}
\hline Parameter & N (\%) & Mean (SD) & Median & $\begin{array}{c}\text { Geometric } \\
\text { mean }\end{array}$ & $\begin{array}{l}\text { Student's t- } \\
\text { test }\end{array}$ & $\begin{array}{c}\text { Wilcoxon } \\
\text { Mann- } \\
\text { Whitney } \\
\end{array}$ \\
\hline \multicolumn{7}{|c|}{ Air change rate in bedroom* } \\
\hline$<1.0 \mathrm{~h}^{-1}$ & $20(36)$ & $75.9(39)$ & 72.2 & 66.1 & & \\
\hline $1.0-1.5 \mathrm{~h}^{-1}$ & $17(30)$ & $74.0(28)$ & 70.2 & 68.9 & & \\
\hline$>1.5 \mathrm{~h}^{-1}$ & $19(34)$ & $68.1(27)$ & 67.3 & 62.8 & & \\
\hline \multicolumn{7}{|c|}{$\begin{array}{l}\text { Having mechanical exhaust } \\
\text { ventilation in bathroom }\end{array}$} \\
\hline No & $42(75)$ & $72.4(32)$ & 68.1 & 65.8 & & \\
\hline Yes & $14(25)$ & $73.3(32)$ & 74.6 & 65.6 & & \\
\hline \multicolumn{7}{|l|}{ Area of dwelling } \\
\hline$<90 \mathrm{~m}^{2}$ & $19(34)$ & 76.9 & 71.8 & 70.8 & & \\
\hline $90-120 \mathrm{~m}^{2}$ & $19(34)$ & 72.6 & 80.2 & 68.2 & & \\
\hline$>120 \mathrm{~m}^{2}$ & $18(32)$ & 68.2 & 55.7 & 58.6 & & \\
\hline \multicolumn{7}{|c|}{$\begin{array}{l}\text { Vicinity to heavily trafficked } \\
\text { road }\end{array}$} \\
\hline$<50 \mathrm{~m}(1)$ & $23(41)$ & 82.5 & 79.0 & 74.2 & $1-3 * *$ & $1-3 * *$ \\
\hline $50-250 \mathrm{~m}(2)$ & $25(45)$ & 68.3 & 62.9 & 62.3 & & \\
\hline$>250 \mathrm{~m}(3)$ & $8(14)$ & 58.2 & 58.2 & 55.1 & & \\
\hline \multicolumn{7}{|l|}{ House type } \\
\hline Family house $(\mathrm{H})$ & $15(27)$ & 52.6 & 54.6 & 48.9 & $\mathrm{H}-\mathrm{A}^{* * *}$ & $\mathrm{H}-\mathrm{A}^{* * *}$ \\
\hline Apartment (A) & $41(73)$ & 80.0 & 79.0 & 73.3 & & \\
\hline \multicolumn{7}{|l|}{ No. of occupants } \\
\hline 1 & $18(32)$ & 77.2 & 72.2 & 70.1 & & \\
\hline 2 & $26(46)$ & 74.1 & 72.9 & 67.1 & & \\
\hline 3 or 4 & $12(21)$ & 62.8 & 52.3 & 57.3 & & \\
\hline \multicolumn{7}{|l|}{ Having a gas stove } \\
\hline No & $33(59)$ & 67.5 & 65.0 & 60.3 & & \\
\hline Yes & $23(41)$ & 80.0 & 75.6 & 74.6 & & \\
\hline
\end{tabular}

* Only four homes had an air exchange rate lower than $0.5 \mathrm{~h}^{-1}$

** Nearly significant, p-value between 0.05 and 0.08

$* * * \mathrm{p}<0.01$ 
Table S3. Daily integrated PN exposure from source events (all analyzed peaks above their respective background concentrations) $\left(\times 10^{3} \mathrm{~cm}^{-3} \mathrm{~h} / \mathrm{d}\right)$ stratified on selected building characteristics $(\mathrm{n}=56)$.

\begin{tabular}{|c|c|c|c|c|c|c|}
\hline Parameter & N (\%) & Mean (SD) & Median & $\begin{array}{c}\text { Geometric } \\
\text { mean }\end{array}$ & $\begin{array}{c}\text { Student's t- } \\
\text { test }\end{array}$ & $\begin{array}{c}\text { Wilcoxon } \\
\text { Mann- } \\
\text { Whitney }\end{array}$ \\
\hline \multicolumn{7}{|c|}{ Air change rate in bedroom } \\
\hline$<1.0 \mathrm{~h}^{-1}$ & $20(36)$ & $562(696)$ & 159 & 196 & & \\
\hline $1.0-1.5 \mathrm{~h}^{-1}$ & $17(30)$ & $858(1488)$ & 158 & 245 & & \\
\hline$>1.5 \mathrm{~h}^{-1}$ & $19(34)$ & $346(434)$ & 133 & 159 & & \\
\hline \multicolumn{7}{|c|}{$\begin{array}{l}\text { Having mechanical exhaust } \\
\text { ventilation in bathroom }\end{array}$} \\
\hline No & $42(75)$ & $602(1057)$ & 157 & 200 & & \\
\hline Yes & $14(25)$ & $509(583)$ & 227 & 183 & & \\
\hline \multicolumn{7}{|l|}{ Area of dwelling } \\
\hline$<90 \mathrm{~m}^{2}(1)$ & $19(34)$ & $880(1392)$ & 338 & 324 & & $1-3 *$ \\
\hline $90-120 \mathrm{~m}^{2}(2)$ & $19(34)$ & $584(749)$ & 157 & 213 & & \\
\hline$>120 \mathrm{~m}^{2}(3)$ & $18(32)$ & $255(322)$ & 113 & 105 & & \\
\hline \multicolumn{7}{|c|}{$\begin{array}{l}\text { Vicinity to heavily trafficked } \\
\text { road }\end{array}$} \\
\hline$<50 \mathrm{~m}$ & $23(41)$ & $653(1293)$ & 158 & 197 & & \\
\hline $50-250 \mathrm{~m}$ & $25(45)$ & $539(723)$ & 133 & 162 & & \\
\hline$>250 \mathrm{~m}$ & $8(14)$ & $488(345)$ & 459 & 344 & & \\
\hline \multicolumn{7}{|l|}{ House type } \\
\hline Family house $(\mathrm{H})$ & $15(27)$ & $200(258)$ & 96 & 93 & $\mathrm{H}-\mathrm{A}^{* *}$ & $\mathrm{H}-\mathrm{A} *$ \\
\hline Apartment (A) & $41(73)$ & $717(1078)$ & 294 & 256 & & \\
\hline \multicolumn{7}{|l|}{ No. of occupants } \\
\hline 1 & $18(32)$ & $802(1511)$ & 149 & 190 & & \\
\hline 2 & $26(46)$ & $540(575)$ & 275 & 218 & & \\
\hline 3 or 4 & $12(21)$ & $328(379)$ & 138 & 161 & & \\
\hline \multicolumn{7}{|l|}{ Having a gas stove } \\
\hline No & $33(59)$ & $446(637)$ & 136 & 144 & & \\
\hline Yes & $23(41)$ & $770(1278)$ & 213 & 303 & & \\
\hline
\end{tabular}

$* \mathrm{p}<0.05$

$* * \mathrm{p}<0.01$ 
Table S4. Total residential daily integrated PN exposure $\left(\times 10^{3} \mathrm{~cm}^{-3} \mathrm{~h} / \mathrm{d}\right)$ stratified on selected building characteristics $(\mathrm{n}=56)$.

\begin{tabular}{|c|c|c|c|c|c|c|}
\hline Parameter & $\mathbf{N}(\%)$ & Mean (SD) & Median & $\begin{array}{c}\text { Geometric } \\
\text { mean }\end{array}$ & $\begin{array}{l}\text { Student's t- } \\
\text { test }\end{array}$ & $\begin{array}{c}\text { Wilcoxon } \\
\text { Mann- } \\
\text { Whitney } \\
\end{array}$ \\
\hline \multicolumn{7}{|c|}{ Air change rate in bedroom } \\
\hline$<1.0 \mathrm{~h}^{-1}$ & $20(36)$ & $655(712)$ & 305 & 338 & & \\
\hline $1.0-1.5 \mathrm{~h}^{-1}$ & $17(30)$ & 945 (1489) & 245 & 402 & & \\
\hline$>1.5 \mathrm{~h}^{-1}$ & 19 (34) & $430(444)$ & 205 & 279 & & \\
\hline \multicolumn{7}{|c|}{$\begin{array}{l}\text { Having mechanical exhaust } \\
\text { ventilation in bathroom }\end{array}$} \\
\hline No & $42(75)$ & $690(1062)$ & 237 & 336 & & \\
\hline Yes & $14(25)$ & $597(600)$ & 315 & 327 & & \\
\hline \multicolumn{7}{|l|}{ Area of dwelling } \\
\hline$<90 \mathrm{~m}^{2}(1)$ & $19(34)$ & 974 (1392) & 394 & 482 & & $1-3^{*}$ \\
\hline $90-120 \mathrm{~m}^{2}(2)$ & $19(34)$ & $671(761)$ & 239 & 358 & & \\
\hline$>120 \mathrm{~m}^{2}(3)$ & $18(32)$ & $338(338)$ & 168 & 210 & & \\
\hline \multicolumn{7}{|c|}{$\begin{array}{l}\text { Vicinity to heavily trafficked } \\
\text { road }\end{array}$} \\
\hline$<50 \mathrm{~m}$ & $23(41)$ & $753(1290)$ & 239 & 348 & & \\
\hline $50-250 \mathrm{~m}$ & $25(45)$ & $616(738)$ & 220 & 294 & & \\
\hline$>250 \mathrm{~m}$ & $8(14)$ & $576(376)$ & 539 & 438 & & \\
\hline \multicolumn{7}{|l|}{ House type } \\
\hline Family house $(\mathrm{H})$ & $15(27)$ & $268(267)$ & 148 & 181 & $\mathrm{H}-\mathrm{A}^{* *}$ & $\mathrm{H}-\mathrm{A}^{*}$ \\
\hline Apartment (A) & $41(73)$ & $813(1081)$ & 386 & 417 & & \\
\hline \multicolumn{7}{|l|}{ No. of occupants } \\
\hline 1 & $18(32)$ & $891(1508)$ & 228 & 344 & & \\
\hline 2 & $26(46)$ & $631(595)$ & 363 & 363 & & \\
\hline 3 or 4 & $12(21)$ & $409(400)$ & 203 & 265 & & \\
\hline \multicolumn{7}{|l|}{ Having a gas stove } \\
\hline No & $33(59)$ & $526(647)$ & 221 & 266 & & \\
\hline Yes & $23(41)$ & $868(1280)$ & 291 & 461 & & \\
\hline
\end{tabular}

\section{Comparison of daily integrated exposure to results from California and Beijing}

Due to their location, the studied dwellings are representative of residential buildings in Copenhagen. Given the types of houses and their building characteristics they well represent the Danish building stock. However, as occupant behavior strongly influences the indoor UFP concentrations (in contrast to building characteristics), our results have global implications. The residential daily integrated exposures in our study were higher than the results obtained from residencies both in California and Beijing. Although our exposure results are influenced by extensive candle burning (occurring in $50 \%$ of homes, often up to several hours per day), they have significant implications. The analyzed source events, including candle burning, are common in many countries. Candle burning can be extensive (e.g., in other Scandinavian countries) or occasional (e.g., in the U.S.). Similar contributions of other indoor sources to UFP exposure were observed in Denmark and California. A larger contribution of outdoor particles to the total UFP exposure was observed in Beijing, presumably due to extremely high 
outdoor PN concentrations in Beijing. In all three countries most of the residential daily integrated exposure occurred while the occupants were awake (Table S5).

Table S5. Comparison of the daily integrated PN exposures obtained in California ${ }^{12}$, Beijing ${ }^{13}$ and Copenhagen, Denmark.

\begin{tabular}{|c|c|c|c|}
\hline Country & $\begin{array}{l}\text { Total residential } \\
\text { daily int. PN exp. (x } \\
\left.\qquad 10^{3} \mathrm{~cm}^{-3} \mathrm{~h} / \mathrm{d}\right)\end{array}$ & $\begin{array}{c}\text { Daily int. PN exp. } \\
\text { during waking hours } \\
+ \text { asleep (x 10 } \mathrm{cm}^{-3} \\
\text { h/d) }\end{array}$ & $\begin{array}{c}\text { Daily int. PN exp. } \\
\text { attributable to } \\
\text { outdoor }+ \text { indoor } \\
\text { sources }\left(x 1^{3} \mathrm{~cm}^{-3}\right. \\
\text { h/d) }\end{array}$ \\
\hline \multicolumn{4}{|l|}{ California: } \\
\hline Arithmetic mean & 296 & 235 awk +63 aslp** & 86 out +205 in $* *$ \\
\hline Geometric mean & 244 & NA & 77 out +129 in \\
\hline \multicolumn{4}{|l|}{ Beijing: } \\
\hline Arithmetic mean & 294 & 220 awk +73 aslp* & 241 out +119 in $* * *$ \\
\hline Geometric mean & $226^{*}$ & 175 awk +41 aslp* & 241 out +100 in $* * *$ \\
\hline \multicolumn{4}{|l|}{ Denmark: } \\
\hline Arithmetic mean & 667 & 605 awk +62 aslp & 74 out +593 in $* * * *$ \\
\hline Geometric mean & 334 & 293 awk +30 aslp & 67 out +212 in $* * * *$ \\
\hline
\end{tabular}

Data from California is based on 21 subjects in 7 homes; data from Beijing is based on 13 subjects in 4 homes, except the apportionment to indoor/outdoor sources, which is based on 4 subjects in 2 homes; data in Denmark is based on 56 homes. The instrument used in California and Beijing measured particles above $6 \mathrm{~nm}$ in diameter (TSI Model 3781 water-based condensation particle counter); the instrument used in Denmark measured particles above 10 nm (Philips NanoTracer).

* Calculated from Figure 2 in Mullen et al. ${ }^{13}$

** As reported in Mullen et al. ${ }^{13}$

$* * *$ Calculated from Figure 3 in Mullen et al. ${ }^{13} ; \mathrm{n}=4$

**** The outdoor fraction was calculated as the background daily exposure + daily exposure from window opening events. The indoor fraction is the remaining exposure to the total residential daily integrated exposure.

\section{Air exchange rates in the 56 homes}

The concentration of $\mathrm{CO}_{2}$ in the bedrooms was continuously measured over the two-day period. The occupancy of the bedroom during each night was recorded by the occupants in order to estimate the $\mathrm{CO}_{2}$ emission rate over the measured period. Ventilation rates were calculated using a mass balance for the occupant-generated $\mathrm{CO}_{2}$ concentrations obtained during the periods of the night when the occupants slept in the room. The measurements, ventilation rate calculations and potential limitations of this method were analogous to those described in Bekö et al. ${ }^{17}$

The air exchange rates in the 56 homes were log-normally distributed (Figure S5). Approximately 7\% of homes had an air exchange rate lower than $0.5 \mathrm{~h}^{-1}$, which is the minimum ventilation rate recommended by the Danish building code. $45 \%$ of the bedrooms had an average $\mathrm{CO}_{2}$ concentration above $1000 \mathrm{ppm}$ during the measured nights. The ventilation rates were relatively high compared to similar studies in Scandinavia. The geometric mean of the air exchange rates was 1.2 h-1 (GSD: 1.98; Mean: $1.6 \mathrm{~h}^{-1}$; SD: $1.35 \mathrm{~h}^{-1}$ ). In homes where the occupants reported having mechanical exhaust ventilation in the bathroom, the air exchange rate was slightly higher (GM: $1.5 \mathrm{~h}^{-1}$ ) compared to homes without such ventilation (GM: $1.2 \mathrm{~h}^{-1}$ ). However, the difference was not statistically significant. 


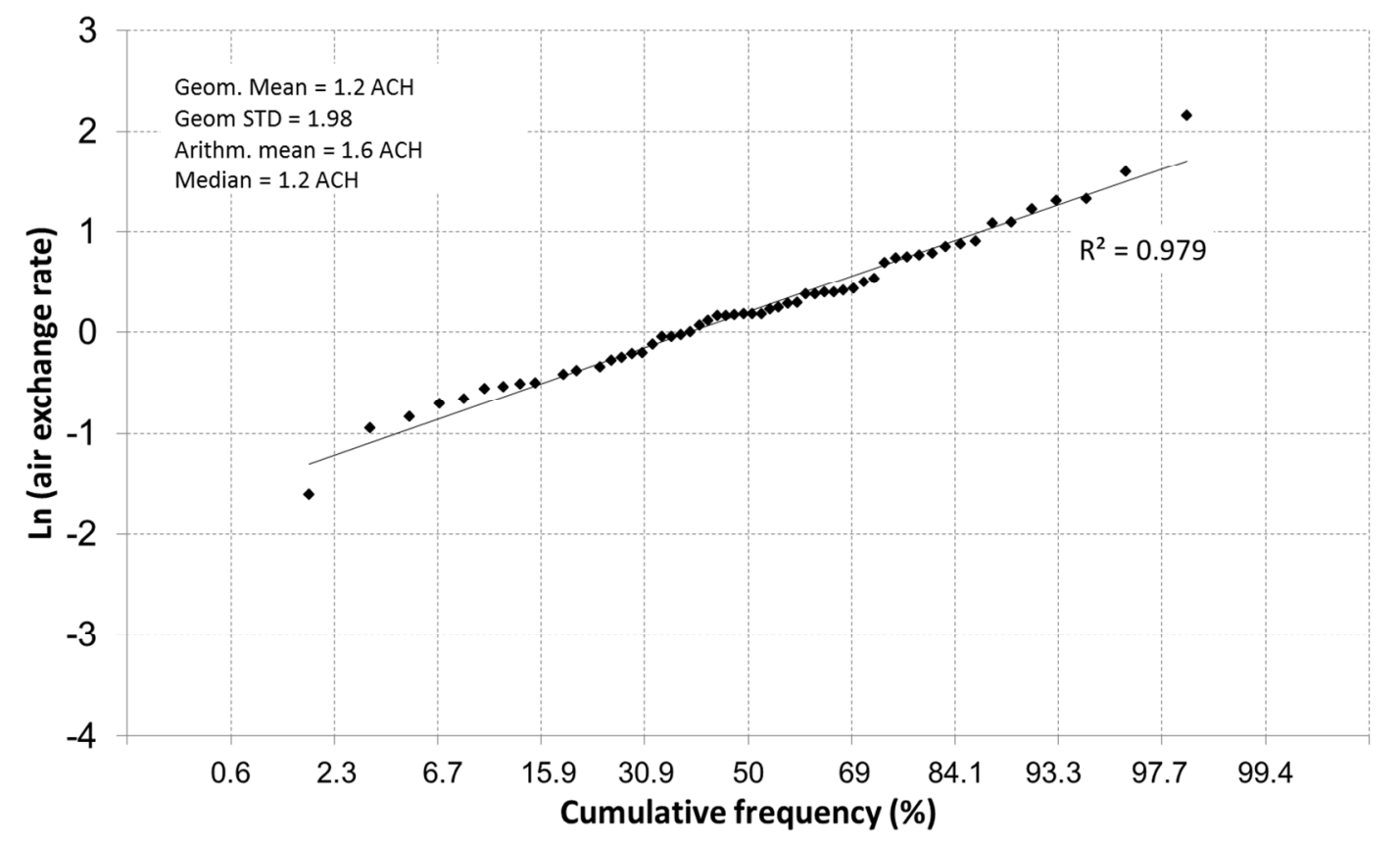

Figure S5. Log-normal distribution of the air exchange rates measured in the bedrooms of the 56 residencies.

\section{References}

1. Asbach, C.; Kaminski, H.; Von Barany, D.; Kuhlbusch, T.A.J.; Monz, C.; Dziurowitz, N.; Pelzer, J.; Vossen, K.; Berlin, K.; Dietrich, S.; Goetz, U.; Kiesling, H.; Schierl, R.; Dahmann, D. Comparability of Portable Nanoparticle Exposure Monitors. Ann. Occup. Hyg. 2012, 56, 606-621.

2. Marra, J.; Voetz, M.; Kiesling, H. Monitor for detecting and assessing exposure to airborne nanoparticles. Journal of Nanoparticle Research 2010, 12, 21-37.

3. Stabile, L.; Fuoco, F.C.; Buonanno, G. Characteristics of particles and black carbon emitted by combustion of incenses, candles and anti-mosquito products. Build. Environ. 2012, 56, 184-191.

4. Pagels, J.; Wierzbicka, A.; Nilsson, E.; Isaxon, C.; Dahl, A.; Gudmundsson, A.; Swietlicki, E.; Bohgard, M. Chemical composition and mass emission factors of candle smoke particles. J. Aerosol Sci. 2009, 40, 193-208.

5. Wallace, L. Indoor sources of ultrafine and accumulation mode particles: Size distributions, sizeresolved concentrations, and source strengths. Aerosol Science and Technology 2006, 40, 348-360.

6. Sun, Z.; Huang, Z.; Wang, J. Studies on the size distribution, number and mass emission factors of candle particles characterized by modes of burning. J. Aerosol Sci. 2006, 37, 1484-1496. 
7. Marra, J.; Van Den Brink, W.; Goossens, H.; Kessels, S. Nanoparticle monitoring for exposure assessment. IEEE Nanotechnology Magazine 2009, 3(2), 6-37; DOI 10.1109/MNANO.2009.932417.

8. Zhu, Y.F.; Hinds, W.C.; Krudysz, M.; Kuhn, T.; Froines, J.; Sioutas, C. Penetration of freeway ultrafine particles into indoor environments. J. Aerosol Sci. 2005, 36, 303-322.

9. Kearney, J.; Wallace, L.; MacNeill, M.; Xu, X.; VanRyswyk, K.; You, H.; Kulka, R.; Wheeler, A.J. Residential indoor and outdoor ultrafine particles in Windsor, Ontario. Atmos. Environ. 2011, 45, 75837593.

10. Hussein, T.; Glytsos, T.; Ondracek, J.; Dohanyosova, P.; Zdimal, V.; Hameri, K.; Lazaridis, M.; Smolik, J.; Kulmala, M. Particle size characterization and emission rates during indoor activities in a house. Atmos. Environ. 2006, 40, 4285-4307.

11. Wallace, L.; Wang, F.; Howard-Reed, C.; Persily, A. Contribution of Gas and Electric Stoves to Residential Ultrafine Particle Concentrations between 2 and 64 nm: Size Distributions and Emission and Coagulation Rates. Environ. Sci. Technol. 2008, 42, 8641-8647.

12. Bhangar, S.; Mullen, N.A.; Hering, S.V.; Kreisberg, N.M.; Nazaroff, W.W. Ultrafine particle concentrations and exposures in seven residences in northern California. Indoor Air 2011, 21, 132-144.

13. Mullen, N.A.; Liu, C.; Zhang, Y.; Wang, S.; Nazaroff, W.W. Ultrafine particle concentrations and exposures in four high-rise Beijing apartments. Atmos. Environ. 2011, 45, 7574-7582.

14. Mullen, N.A.; Bhangar, S.; Hering, S.V.; Kreisberg, N.M.; Nazaroff, W.W. Ultrafine particle concentrations and exposures in six elementary school classrooms in northern California. Indoor Air 2011, 21, 77-87.

15. Wallace, L. and Ott, W. Personal exposure to ultrafine particles. Journal of Exposure Science and Environmental Epidemiology 2011, 21, 20-30.

16. Rim, D.; Wallace, L.; Persily, A. Infiltration of Outdoor Ultrafine Panicles into a Test House. Environ. Sci. Technol. 2010, 44, 5908-5913.

17. Beko, G.; Lund, T.; Nors, F.; Toftum, J.; Clausen, G. Ventilation rates in the bedrooms of 500 Danish children. Build. Environ. 2010, 45, 2289-2295. 